\title{
How to Define Transarterial Chemoembolization Failure or Refractoriness: A European Perspective
}

\author{
Jean-Luc Raoul ${ }^{a}$ Marine Gilabert ${ }^{a} \quad$ Gilles Piana $^{b}$

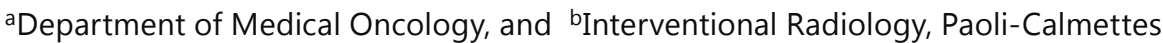 \\ Institute, Marseille, France
}

\section{Key Words}

Hepatocellular carcinoma $\cdot$ Intermediate stage $\cdot$ Transarterial chemoembolization

\begin{abstract}
In Europe, trans-arterial chemoembolization (TACE) is usually given to patients with Barcelona Clinic Liver Cancer (BCLC) "intermediate stage" hepatocellular carcinoma (HCC), and is associated with a modest improvement in median overall survival. In the two positive randomized trials that have been reported, TACE was stopped in cases of severe toxicity, worsening of liver cirrhosis or performance status and tumor progression, including local progression, extrahepatic spread and portal vein thrombosis. The necessity to stop TACE leads to the concept of untreatable progression, which is characterized by massive liver involvement, extrahepatic spread, vascular invasion, impaired liver function or performance status. More recently, the assessment for re-treatment with TACE (ART) score has been developed to determine which patients will not benefit from a second or a third TACE therapy. Herein, we propose an algorithm that summarizes our experience with TACE.Copyright $\odot 2014 \mathrm{~S}$. Karger AG, Basel
\end{abstract}

\section{Introduction}

HCC is a frequent cancer that is among the leading causes of cancer deaths [1] worldwide. Most cases are associated with an underlying liver disease, usually liver cirrhosis, and HCC is the leading cause of death among cirrhotic patients [2]. This justifies the development of surveillance programs based on the use of abdominal ultrasound [3]. The treatment of 
HCC is based on various classification systems. In Europe and in the US, the most commonly used staging system is the BCLC allocation system, which links prognostic factors, stages (4 stages) and therapeutic proposal [4]. In the staging system, the intermediate stage is defined by large, unresectable or multinodular HCC in patients with excellent performance status (PS 0) with Child-Pugh A or B liver cirrhosis. For these patients, the best therapeutic option is trans-arterial chemoembolization (TACE) [5]. TACE was recommended for these patients after two positive, randomized controlled trials were reported which used either doxorubicin [6] or cisplatin [7] as the chemotherapeutic agent. Additionally, a meta-analysis [8] demonstrated an improvement in patients' median overall survival from 16 months, with best supportive care alone, to 20 months after TACE. However, these studies suffered from a lack of standardization [9] in patient selection, chemotherapeutic agents used, retreatment schedule, discontinuing rules and the skill of the interventional radiologists. In Europe, TACE is usually restricted to intermediate stage patients, excluding those with decompensated cirrhosis (stage B8 and over), extensive tumor, renal insufficiency, large tumor size $(>10 \mathrm{~cm})$, comorbidities and portal vein thrombosis $[10,11]$. In a randomized phase II trial [12], a novel drug delivery system (drug eluding beads) loaded with doxorubicin was shown to have similar efficacy, but was better tolerated than conventional TACE. Moreover, this technique seems reproducible and has been used with increasingly promising results, particularly in patients with minor tumor burden and well-compensated liver cirrhosis $[4,13]$. The indications for TACE are still debated and vary between centers and countries. Furthermore, the discontinuing rules are even less clear, and limited data are available on this subject, mainly because there are no well defined criteria for TACE failure and refractoriness. Taking into account the possible risks and the limited survival benefit of TACE, physicians have to avoid adverse effects that will outweigh the survival benefit, and determine when continuing treatment is an ineffective therapeutic option. Moreover, studies that have demonstrated the efficacy of sorafenib $[14,15]$ have shown that contraindications to or the discontinuing of TACE is not associated with the end of treatment, because sorafenib has been demonstrated to be as efficient in patients after TACE failure [16]; this concept of treatment stage migration [17] has led to sorafenib being offered to BCLC stage B patients who have failed to respond to TACE, or who have progressed after TACE. This paper will focus on the definition of TACE failure or refractoriness from a European perspective. The difference between failure and refractoriness is subtle, as both will lead to considerations that TACE is not useful. Accordingly, we will consider a failure as a worsening of either the tumor size or liver function or performance status, and refractoriness as a lack of efficacy of the treatment.

\section{Discontinuing Rules in Two Positive Randomized Controlled Trials}

In the study from Lo et al. [7], TACE was repeated every 2 to 3 months and was discontinued in cases of poor hepatic function, severe adverse effects, or progressive disease. Poor hepatic function was defined as the following: hepatic encephalopathy, ascites not controlled by diuretics, variceal bleeding, serum bilirubin over $50 \mu \mathrm{mol} / \mathrm{L}$, serum albumin level below $28 \mathrm{~g} / \mathrm{L}$ or a prothrombin time of more than 4 seconds over the control. The definition of progression was based on computer tomography (CT) scans of tumor size and an increase in the serum $\alpha$-fetoprotein levels by more than $25 \%$. In this series, the reasons for discontinuation were as follows: progressive disease in 12 , death in 7 , poor liver function in 6 , adverse events in 6 , patient refusal in 3 , arteriovenous shunting in 2 , and hepatic artery thrombosis in 2 patients. The 2 -year overall survival was only $11 \%$ in the control group but was $31 \%$ in the TACE group. In a multivariate analysis, only two factors were of prognostic value, namely 
the treatment group and the presence of a unilobar portal vein obstruction. Specifically, the 2 -year overall survival was $27 \%$ in the absence of portal vein obstruction, but $5 \%$ in its presence.

In the trial reported by Llovet et al [8], TACE was performed at baseline, 2 months, and 6 months followed by every 6 months thereafter. The tumor response to treatment was assessed by CT scan. Treatment was discontinued at the patient's request or if any of the following exclusion criteria developed: Child-Pugh C, active gastrointestinal bleeding, encephalopathy, refractory ascites, and the presence of vascular invasion, including segmental portal obstruction. Progressive disease led to the discontinuation of TACE in cases of vascular invasion or extrahepatic spread. The reasons for treatment discontinuation in the TACE group were as follows: 9 cases of tumor progression (including worsening of performance status), 8 cases of technical problems, 4 severe adverse events, 4 patient's decision, 4 deaths and 2 cases of liver failure without progression. The 2-year overall survival was 63\% in the TACE group and $27 \%$ in the control group, respectively.

\section{Concept of Untreatable / UnTACEable Tumor Progression}

TACE is a loco-regional treatment, and some usual oncologic parameters, such as time to progression, are not valid, as local tumor progression can sometimes benefit from new TACE sessions. In contrast, major local progression, but also hepatic responses or stabilizations associated with portal vein invasion or extrahepatic progression, will not benefit from TACE, but will require systemic treatment. According to Bruix et al., [18] untreatable tumor progression includes massive liver involvement, extrahepatic spread and vascular invasion as well as minor hepatic progression, if associated with impaired liver function or performance status.

It is obvious that extrahepatic metastases can develop despite TACE efficacy with eventual complete response. Even though such cases are infrequent, they must be considered as TACE failure because the disease itself was not fully controlled.

\section{ART Score}

The toxicity and efficacy of retreatment with TACE are related to tumor and liver parameters. Sieghart et al. [19] conducted a multivariate analysis, and found three prognostic factors namely an increase in aspartate transaminase (AST) level by more than $25 \%$, an increase in the Child-Pugh score and the absence of tumor response, which were used to develop the ART score, which calculates the prognosis if a second TACE is given. In their series, patients with an ART score of 0-1.5 points benefitted from a second TACE session, while those with a score $\geq 2.5$ did not benefit, respectively. Next, the authors proposed to combine the ART score with a previous algorithm to better define patients who would benefit from the continuation of TACE, and those who would require switching to another therapeutic option. More recently, they demonstrated that the ART score was also of value for deciding the potential benefit of undergoing a third TACE [20]. For some authors, the ART score is not considered as a universal point scoring system, particularly in Japan [21], where TACE is given to patients with a lower tumor burden than in Austria or in France, and of whom the majority have hepatitis $\mathrm{C}$ virus-induced liver diseases [22].

The definition of refractoriness mainly depends on the goal. If one considers TACE to be a palliative treatment, the stabilization of disease can be considered a positive outcome. In contrast, if TACE is considered, in some instances, as a potential cure, stable disease would 


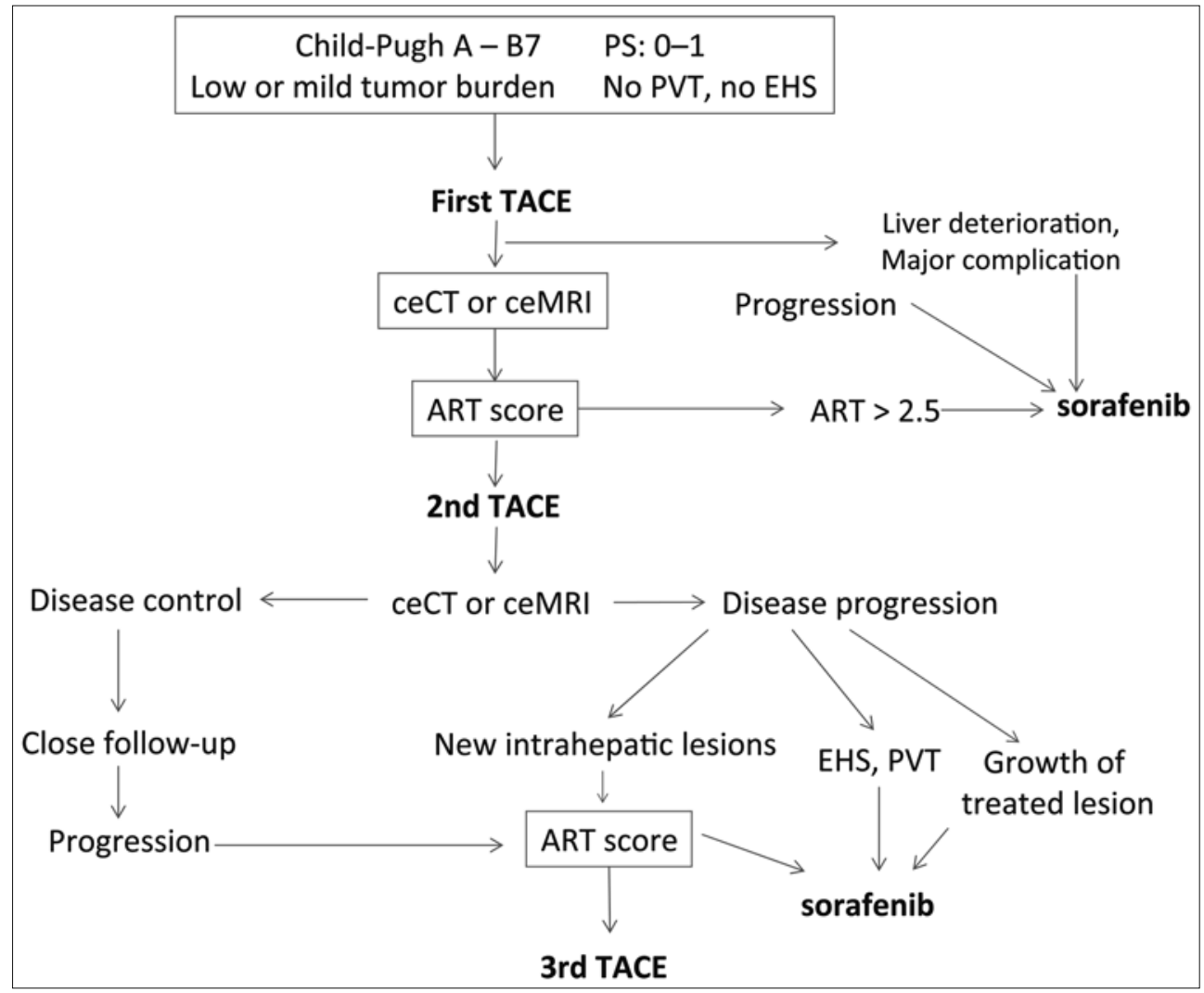

Fig. 1. Proposed algorithm for TACE. PVT=portal vein thrombosis; EHS=extrahepatic spread; ceCT=contrast enhanced CT scan; ceMRI=contrast enhanced MRI.

be considered a negative outcome, and it could be viewed that the disease is refractory to TACE. These two options are discussed in two different algorithms. For Raoul et al. [10], stable disease after two TACE sessions is considered as sufficient to propose a "wait-and-see policy"; that is, patients will be followed-up closely to re-TACE them if there is progression. In contrast, Bruix et al. [18] consider the absence of tumor response as TACE refractoriness, and these patients will be treated by other means.

\section{Proposition of a New Algorithm for TACE (fig. 1)}

Candidates for TACE include BCLC stage B patients with good performance status, ChildPugh A or B7 liver cirrhosis, without extra hepatic spread or portal vein invasion (including segmental thrombosis), with mild or low tumor burden. After the first TACE, in cases of severe adverse events or liver deterioration (Child-Pugh score), the TACE program is stopped and sorafenib is offered to these patients. A contrast-enhanced CT scan or magnetic resonance imaging (MRI) is performed 4 to 6 weeks after this first TACE. In cases of progression, TACE has to be stopped, and sorafenib is considered the best option. In cases of stability or response some days prior to the planned second TACE, the ART score will be calculated. In cases of high scores $(\geq 2.5)$, it seems prudent to stop TACE and switch to systemic treatments. If not, a second TACE will be given, which will be followed 4 to 6 weeks later by a contrast enhanced CT or MRI. In cases of controlled disease (response or stable disease), 
a wait-and-see policy will be applied with a regular follow-up (every 2 to 3 months). If the tumor progresses, a third TACE can be given, if the ART score remains low. If after the second TACE there is evidence of untreatable tumor progression, including extrahepatic spread, portal vein thrombosis and the growth of the previously TACE-treated lesion, sorafenib will be given. In cases of progression outside of the pre-treated field, a third TACE can be given if indicated by the ART score.

\section{Conclusion}

In conclusion, the definition of TACE failure or refractoriness is very much dependent on the indications of TACE. In contrast to Japan, in Western countries, the diagnosis is frequently made at "advanced stages" with severe underlying cirrhosis. In such cases, the goal of TACE is usually to control the disease for several more months, and severe toxicity or minor progression usually leads to switching to another treatment, to avoid worsening of liver function and poorer outcome. There is certainly room for improvement with the ART score, but it can certainly be useful in such patients. In patients with very localized tumors treated with supraselective TACE and those with well-compensated cirrhosis, one single session can be very effective and can control the disease for months or years. In such cases, retreatment is certainly the best way to control the tumor for a prolonged period, but these patients are certainly more frequent in Japan than in Europe.

\section{References}

1 Globocan 2012; http://globocan.iarc.fr.

2 Fattovich G, Giustina G, Degos F, Tremolada F, Diodati G, Almasio P, Nevens F, Solinas A, Mura D, Brouwer JT, Thomas H, Njapoum C, Casarin C, Bonetti P, Fuschi P, Basho J, Tocco A, Bhalla A, Galassini R, Noventa F, Schalm SW, Realdi G: Morbidity and mortality in compensated cirrhosis type C: a retrospective follow-up study of 384 patients. Gastroenterology 1997;112:463-472.

-3 Kudo M: Japan's successful model of nationwide hepatocellular carcinoma surveillance highlighting the urgent need for global surveillance. Liver Cancer 2012;1:141-143.

4 Forner A, Llovet JM, Bruix J: Hepatocellular carcinoma. Lancet 2012;379:1245-1255.

5 Lencioni R: Chemoembolization in patients with hepatocellular carcinoma. Liver Cancer 2012;1:41-50.

-6 Llovet JM, Real MI, Montaña X, Planas R, Coll S, Aponte J, Ayuso C, Sala M, Muchart J, Solà R, Rodés J, Bruix J, Barcelona Liver Cancer Group: Arterial embolisation or chemoembolisation versus symptomatic treatment in patients with unresectable hepatocellular carcinoma: a randomised controlled trial. Lancet 2002;359:1734-1739.

-7 Lo CM, Ngan H, Tso WK, Liu CL, Lam CM, Poon RT, Fan ST, Wong J: Randomized controlled trial of transarterial lipiodol chemoembolization for unresectable hepatocellular carcinoma. Hepatology 2002;35:11641171.

8 Llovet JM, Bruix J: Systematic review of randomized trials for unresectable hepatocellular carcinoma: Chemoembolization improves survival. Hepatology 2003;37:429-442.

-9 Tsochatzis EA, Meyer T, O’Beirne J, Burroughs AK: Transarterial therapies for hepatocellular carcinoma (HCC): a long way towards standardization. J Hepatol 2013;58:194-198.

10 Raoul JL, Sangro B, Forner A, Mazzaferro V, Piscaglia F, Bolondi L, Lencioni R: Evolving strategies for the management of intermediate-stage hepatocellular carcinoma: available evidence and expert opinion on the use of transarterial chemoembolization. Cancer Treat Rev 2011;37:212-220.

$>11$ de Lope CR, Tremosini S, Forner A, Reig M, Bruix J: Management of HCC. J Hepatol 2012;56(Suppl 1):S75S87.

12 Lammer J, Malagari K, Vogl T, Pilleul F, Denys A, Watkinson A, Pitton M, Sergent G, Pfammatter T, Terraz S, Benhamou Y, Avajon Y, Gruenberger T, Pomoni M, Langenberger H, Schuchmann M, Dumortier J, Mueller C, Chevallier P, Lencioni R, PRECISION V Investigators: Prospective randomized study of doxorubicin-elutingbead embolization in the treatment of hepatocellular carcinoma: results of the PRECISION V study. Cardiovasc Intervent Radiol 2010;33:41-52.

13 Burrel M, Reig M, Forner A, Barrufet M, de Lope CR, Tremosini S, Ayuso C, Llovet JM, Real MI, Bruix J: Survival of patients with hepatocellular carcinoma treated by transarterial chemoembolisation (TACE) using Drug Eluting Beads. Implications for clinical practice and trial design. J Hepatol 2012;56:1330-1335. 
14 Llovet JM, Ricci S, Mazzaferro V, Hilgard P, Gane E, Blanc JF, de Oliveira AC, Santoro A, Raoul JL, Forner A, Schwartz M, Porta C, Zeuzem S, Bolondi L, Greten TF, Galle PR, Seitz JF, Borbath I, Häussinger D, Giannaris T, Shan M, Moscovici M, Voliotis D, Bruix J, SHARP Investigators Study Group: Sorafenib in advanced hepatocellular carcinoma. N Engl J Med 2008;359:378-390.

15 Cheng AL, Kang YK, Chen Z, Tsao CJ, Qin S, Kim JS, Luo R, Feng J, Ye S, Yang TS, Xu J, Sun Y, Liang H, Liu J, Wang J, Tak WY, Pan H, Burock K, Zou J, Voliotis D, Guan Z: Efficacy and safety of sorafenib in patients in the Asia-Pacific region with advanced hepatocellular carcinoma: a phase III randomised, double-blind, placebo-controlled trial. Lancet Oncol 2009;10:25-34.

-16 Bruix J, Raoul JL, Sherman M, Mazzaferro V, Bolondi L, Craxi A, Galle PR, Santoro A, Beaugrand M, Sangiovanni A, Porta C, Gerken G, Marrero JA, Nadel A, Shan M, Moscovici M, Voliotis D, Llovet JM: Efficacy and safety of sorafenib in patients with advanced hepatocellular carcinoma: subanalyses of a phase III trial. J Hepatol 2012;57:821-829.

$\checkmark 17$ European Association For The Study Of The Liver European Organisation For Research And Treatment Of Cancer: EASL-EORTC clinical practice guidelines: management of hepatocellular carcinoma. J Hepatol 2012;56:908-943.

18 Bruix J, Reig M, Rimola J, Forner A, Burrel M, Vilana R, Ayuso C: Clinical decision making and research in hepatocellular carcinoma: pivotal role of imaging techniques. Hepatology 2011;54:2238-2244.

19 Sieghart W, Hucke F, Pinter M, Graziadei I, Vogel W, Müller C, Heinzl H, Trauner M, Peck-Radosavljevic M: The ART of decision making: retreatment with transarterial chemoembolization in patients with hepatocellular carcinoma. Hepatology 2013;57:2261-2273.

20 Hucke F, Sieghart W, Pinter M, Graziadei I, Vogel W, Müller C, Heinzl H, Waneck F, Trauner M, Peck-Radosavljevic M: The ART-strategy: sequential assessment of the ART score predicts outcome of patients with hepatocellular carcinoma re-treated with TACE. J Hepatol 2014;60:118-126.

21 Kudo M, Arizumi T, Ueshima K: ART score for repeated transarterial chemoembolization in patients with hepatocellular carcinoma. Hepatology 2013 (in press).

22 Kim SR, Kudo M, Hino O, Han KH, Chung YH, Lee HS: Organizing Committee of Japan - Korea liver symposium. Epidemiology of hepatocellular carcinoma in Japan and Korea. A review. Oncology 2008;75 Suppl 1: 13-16. 